\title{
New Class of Plastic Bulk Metallic Glass
}

\author{
L. Y. Chen, ${ }^{1}$ Z. D. Fu, ${ }^{2}$ G. Q. Zhang, ${ }^{1,3}$ X. P. Hao, ${ }^{4}$ Q. K. Jiang, ${ }^{1}$ X. D. Wang, ${ }^{1}$ Q. P. Cao, ${ }^{1}$ H. Franz,${ }^{5}$ Y. G. Liu, ${ }^{6}$ H. S. Xie, ${ }^{6}$ \\ S. L. Zhang, ${ }^{2}$ B. Y. Wang, ${ }^{4}$ Y. W. Zeng, ${ }^{1}$ and J. Z. Jiang ${ }^{1, *}$ \\ ${ }^{1}$ International Center for New-Structured Materials (ICNSM), Zhejiang University and Laboratory of New-Structured Materials, \\ Department of Materials Science and Engineering, Zhejiang University, \\ Hangzhou 310027, People's Republic of China \\ ${ }^{2}$ Department of Physics, Peking University, Beijing 100871, People's Republic of China \\ ${ }^{3}$ Key Laboratory of Advanced Textile Materials and Manufacturing Technology, Zhejiang Sci-Tech University, \\ Hangzhou 310018, People's Republic of China \\ ${ }^{4}$ Institute of High Energy Physics, Chinese Academy of Sciences, Beijing 100049, People's Republic of China \\ ${ }^{5}$ HASYLAB at DESY, Notkestrasse 85, D-22603 Hamburg, Germany \\ ${ }^{6}$ Institute of Geochemistry, Chinese Academy of Sciences, Guiyang 550002, People's Republic of China
}

(Received 9 February 2007; published 20 February 2008)

\begin{abstract}
An intrinsic plastic $\mathrm{Cu}_{45} \mathrm{Zr}_{46} \mathrm{Al}_{7} \mathrm{Ti}_{2}$ bulk metallic glass (BMG) with high strength and superior compressive plastic strain of up to $32.5 \%$ was successfully fabricated by copper mold casting. The superior compressive plastic strain was attributed to a large amount of randomly distributed free volume induced by Ti minor alloying, which results in extensive shear band formation, branching, interaction and self-healing of minor cracks. The mechanism of plasticity presented here suggests that the creation of a large amount of free volume in BMGs by minor alloying or other methods might be a promising new way to enhance the plasticity of BMGs.
\end{abstract}

DOI: 10.1103/PhysRevLett.100.075501

Bulk metallic glasses (BMGs) possess unique mechanical properties, such as large elastic limits (2\%), high strength, and high hardness [1-3]. However, plastic deformation of BMGs is highly localized into shear bands, which usually rapidly propagate across the sample due to strain softening and/or thermal softening [4-6] and initiate a crack, resulting in a limited plastic strain (less than $2 \%$ ) and catastrophic failure at room temperature [2,3]. Recently, bulk metallic glass composites and BMGs with enhanced plasticity during compression were fabricated [7-24]. The enhanced plasticity was attributed to: (1) micrometer-sized structural heterogeneity: (a) micrometer-sized ductile crystalline phase [8-11] or (b) micrometer-sized porosity [12]; (2) nanometer-sized structural heterogeneity: (a) nanocrystallization induced before deformation [13-17] or during deformation [18$20]$ and/or (b) nanometer-scale phase separation (or chemical heterogeneity) [16,21,22]; (3) high Poisson's ratio [23]; (4) sluggish atomic movement kinetics [24]. In this Letter, we present a plastic monolithic $\mathrm{Cu}_{45} \mathrm{Zr}_{46} \mathrm{Al}_{7} \mathrm{Ti}_{2}$ BMG. It exhibits high strength and superior compression plastic deformation of up to $32.5 \%$ at room temperature. The outstanding intrinsic plastic deformability is attributed to randomly distributed free volume, inducing by minor alloying, which results in extensive shear band formation, branching, interaction, and self-healing of minor cracks.

$\mathrm{Cu}_{45} \mathrm{Zr}_{48} \mathrm{Al}_{7}$ and $\mathrm{Cu}_{45} \mathrm{Zr}_{46} \mathrm{Al}_{7} \mathrm{Ti}_{2}$ alloys were prepared by arc melting the mixtures of $\mathrm{Cu}(99.9$ wt. \%), $\mathrm{Zr}$ (99.8 wt. \%), Al (99.9 wt. \%), and Ti (99.9 wt.\%) elements in Ti-gettered high purity argon atmosphere. Cylindrical alloy rods of $2 \mathrm{~mm}$ in diameter were prepared by injecting
PACS numbers: 62.20.F-, 61.43.Dq, 81.05.Kf, 81.40.Lm

alloy melt into copper mold. Structures of samples were examined by x-ray diffractometer (XRD, $\mathrm{Cu} K_{\alpha}$ radiation), high resolution XRD (HRXRD, $100 \mathrm{keV}$, at HASYLAB, Germany), and transmission electron microscope (TEM, Hitachi H-9000NAR). The TEM specimens were prepared by ion milling with liquid nitrogen cooling. Glass transition and crystallization behavior were studied using a NETZSCH DSC 404 C differential scanning calorimeter under a continuous argon flow at a heating rate of $0.33 \mathrm{~K} / \mathrm{s}$. Compression tests were carried out for cylindrical rods $(2 \mathrm{~mm}$ diameter $\times 4 \mathrm{~mm}$ length) using a universal testing machine (CMT5205 SANS, China). Morphology and side surface of deformed samples were observed by field emission scanning electron microscope (FESEM, SIRION-100). The ultrasonic measurements, using a MATEC 6600 model ultrasonic system with a measuring sensitivity of $0.5 \mathrm{~ns}$, were carried out to estimate the acoustic longitudinal velocity $\left(v_{l}\right)$ and shear velocity $\left(v_{s}\right)$ of $\mathrm{Cu}_{45} \mathrm{Zr}_{48} \mathrm{Al}_{7}$ and $\mathrm{Cu}_{45} \mathrm{Zr}_{46} \mathrm{Al}_{7} \mathrm{Ti}_{2}$ BMG alloys. The frequency used for ultrasonic measurements is $5 \mathrm{MHz}$. The free volume was studied by positron annihilation experiments, which were carried out with a fast-slow coincidence ORTEC system with a time resolution of $190 \mathrm{ps}$ (full width at half maximum). The positron source was $5 \times 10^{5}$ $\mathrm{Bq}$ of ${ }^{22} \mathrm{Na}$. The results were analyzed with the POSITRONFIT- 88 program. In addition, density measurements for both $\mathrm{Cu}_{45} \mathrm{Zr}_{48} \mathrm{Al}_{7}$ and $\mathrm{Cu}_{45} \mathrm{Zr}_{46} \mathrm{Al}_{7} \mathrm{Ti}_{2}$ BMG alloys based on the Archimedean principle were also carried out with a Mettler Toledo XS105 microbalance having a sensitivity of $0.01 \mathrm{mg}$. The compositions of ascast $\mathrm{Cu}_{45} \mathrm{Zr}_{46} \mathrm{Al}_{7} \mathrm{Ti}_{2}$ and $\mathrm{Cu}_{45} \mathrm{Zr}_{48} \mathrm{Al}_{7}$ BMGs were examined by energy-dispersive $\mathrm{x}$-ray analysis in FESEM 
and TEM, which are similar to the initial ingot compositions.

The XRD (as shown in Fig. 1S [25]) and DSC (as shown in Fig. 2S [25]) results show the glass nature of the as-cast $\mathrm{Cu}_{45} \mathrm{Zr}_{48} \mathrm{Al}_{7}$ and $\mathrm{Cu}_{45} \mathrm{Zr}_{46} \mathrm{Al}_{7} \mathrm{Ti}_{2}$ alloy rods, which exhibit critical diameter of $6 \mathrm{~mm}$ for forming BMGs. Cylindrical specimens of $2 \mathrm{~mm}$ diameter and $4 \mathrm{~mm}$ length for each composition were prepared from as-cast rods and tested using a universal testing machine at a strain rate of $4 \times$ $10^{-4} \mathrm{~s}^{-1}$ at room temperature. Both ends of the specimens were polished to make them parallel to each other prior to compression tests with about 20 micrometers uncertainty. Figure 1 shows engineering stress vs. strain curves of the $\mathrm{Cu}_{45} \mathrm{Zr}_{48} \mathrm{Al}_{7}$ and $\mathrm{Cu}_{45} \mathrm{Zr}_{46} \mathrm{Al}_{7} \mathrm{Ti}_{2}$ glassy alloys. In order to show the data clearly, curve (b) was shifted to the right $5 \%$. The yielding strength of the $\mathrm{Cu}_{45} \mathrm{Zr}_{48} \mathrm{Al}_{7}$ and $\mathrm{Cu}_{45} \mathrm{Zr}_{46} \mathrm{Al}_{7} \mathrm{Ti}_{2}$ glassy alloys are 1720 and $1820 \mathrm{MPa}$, respectively. After yielding, the $\mathrm{Cu}_{45} \mathrm{Zr}_{46} \mathrm{Al}_{7} \mathrm{Ti}_{2}$ alloy could exhibit large plastic deformation of up to $32.5 \%$ before fracture whereas the $\mathrm{Cu}_{45} \mathrm{Zr}_{48} \mathrm{Al}_{7}$ alloy undergoes about $1.5 \%$ plastic strain before failure. The quaternary alloy reveals superior deformability as compared to the ternary alloy. Note that limited compressive plasticity down to zero and $2 \%$ were also observed for 5 and 4 times among 40 mechanical tests for the $\mathrm{Cu}_{45} \mathrm{Zr}_{48} \mathrm{Al}_{7}$ and $\mathrm{Cu}_{45} \mathrm{Zr}_{46} \mathrm{Al}_{7} \mathrm{Ti}_{2} \mathrm{BMG}$ alloys, respectively. The origin for the scattering data of compressive plasticity for both $\mathrm{BMG}$ alloys is still unclear. Furthermore, the $\mathrm{Cu}_{45} \mathrm{Zr}_{46} \mathrm{Al}_{7} \mathrm{Ti}_{2}$ BMG can be bent and sustain torsional deformation as demonstrated in Fig. S3 [25]. The morphology and side surface of the deformed $\mathrm{Cu}_{45} \mathrm{Zr}_{48} \mathrm{Al}_{7}$ and $\mathrm{Cu}_{45} \mathrm{Zr}_{46} \mathrm{Al}_{7} \mathrm{Ti}_{2}$ BMG rods were investigated using FESEM in Figs. 2, S4, and S5 [25]. It is found that after compression the diameter of the $\mathrm{Cu}_{45} \mathrm{Zr}_{46} \mathrm{Al}_{7} \mathrm{Ti}_{2}$ BMG rod increases from 2 to $2.7 \mathrm{~mm}$, having a strain of about $35 \%$ in the transversal direction. As a comparison, the strain of the $\mathrm{Cu}_{45} \mathrm{Zr}_{48} \mathrm{Al}_{7}$ BMG rod is found to be undetectable along the same direction. Figures 2, S4 and S5 show shear bands on the side surface of $\mathrm{Cu}_{45} \mathrm{Zr}_{48} \mathrm{Al}_{7}$ and $\mathrm{Cu}_{45} \mathrm{Zr}_{46} \mathrm{Al}_{7} \mathrm{Ti}_{2}$ BMG rods after deformation. The shear band spacing for the $\mathrm{Cu}_{45} \mathrm{Zr}_{46} \mathrm{Al}_{7} \mathrm{Ti}_{2}$ BMG alloy is significantly shorter than that for the $\mathrm{Cu}_{45} \mathrm{Zr}_{48} \mathrm{Al}_{7} \mathrm{BMG}$ alloy, which indicates high

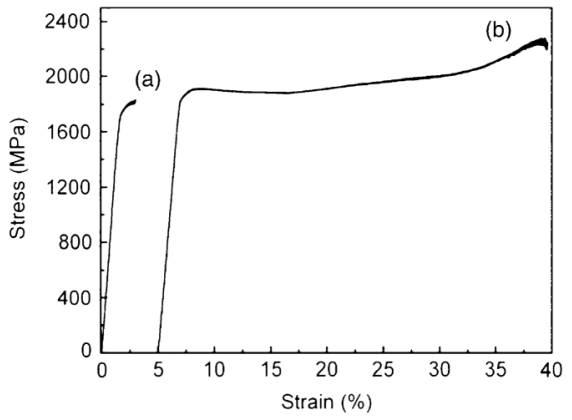

FIG. 1. Engineering stress-strain curves of (a) $\mathrm{Cu}_{45} \mathrm{Zr}_{48} \mathrm{Al}_{7}$ and (b) $\mathrm{Cu}_{45} \mathrm{Zr}_{46} \mathrm{Al}_{7} \mathrm{Ti}_{2}$ BMG alloy rods. nucleation number of shear bands in the quaternary BMG alloy. We also found that the shear bands highly branch and interact in the $\mathrm{Cu}_{45} \mathrm{Zr}_{46} \mathrm{Al}_{7} \mathrm{Ti}_{2}$ BMG alloy, as marked by short (for branch) and long arrows (for interaction) in Fig. S4 (h). The nucleation of large amount of shear bands together with the extensive branch and interaction of the shear bands directly results in the significant plastic deformation demonstrated in Fig. 1.

What do the shear processes illustrated in Fig. 2 originate from? First, we examined the possibility of nanocrystallization and nanometer-scale phase separation (chemical heterogeneity) in as-cast rods. High intensity, high resolution x-ray $(100 \mathrm{keV})$ with beam size of $1 \mathrm{~mm}^{2}$ produced by synchrotron radiation facility in HASYLAB, Germany was used to record HRXRD patterns for as-cast BMG alloys ( $2 \mathrm{~mm}$ rod). A representative HRXRD pattern recorded from the as-cast $\mathrm{Cu}_{45} \mathrm{Zr}_{46} \mathrm{Al}_{7} \mathrm{Ti}_{2}$ alloy is shown in Fig. 3(a). No sharp Bragg peaks superimposing on the curve were detected, confirming amorphous structure of the as-cast $\mathrm{Cu}_{45} \mathrm{Zr}_{46} \mathrm{Al}_{7} \mathrm{Ti}_{2}$ BMG rod. We further per-

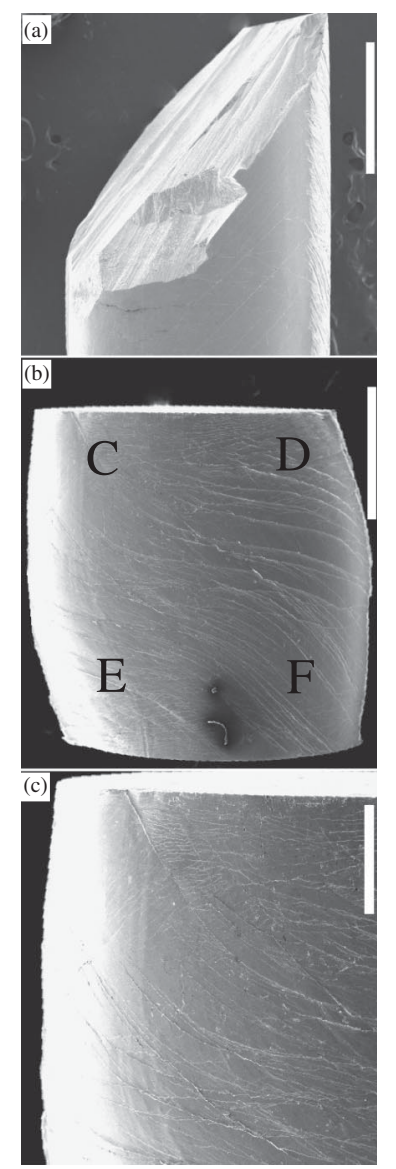

FIG. 2. (a) Morphology of fractured $\mathrm{Cu}_{45} \mathrm{Zr}_{48} \mathrm{Al}_{7}$ alloy; (b) morphology of $\mathrm{Cu}_{45} \mathrm{Zr}_{46} \mathrm{Al}_{7} \mathrm{Ti}_{2}$ BMG alloy rod with compressive plastic strain of about $30 \%$; (c) enlargement of part C in (b). Enlargement of part D,E, and F in (b) are shown in Fig. S5 of [25]. The length of the scale bars for (a) and (b) is $1 \mathrm{~mm}$ and for (c) is $0.5 \mathrm{~mm}$. 

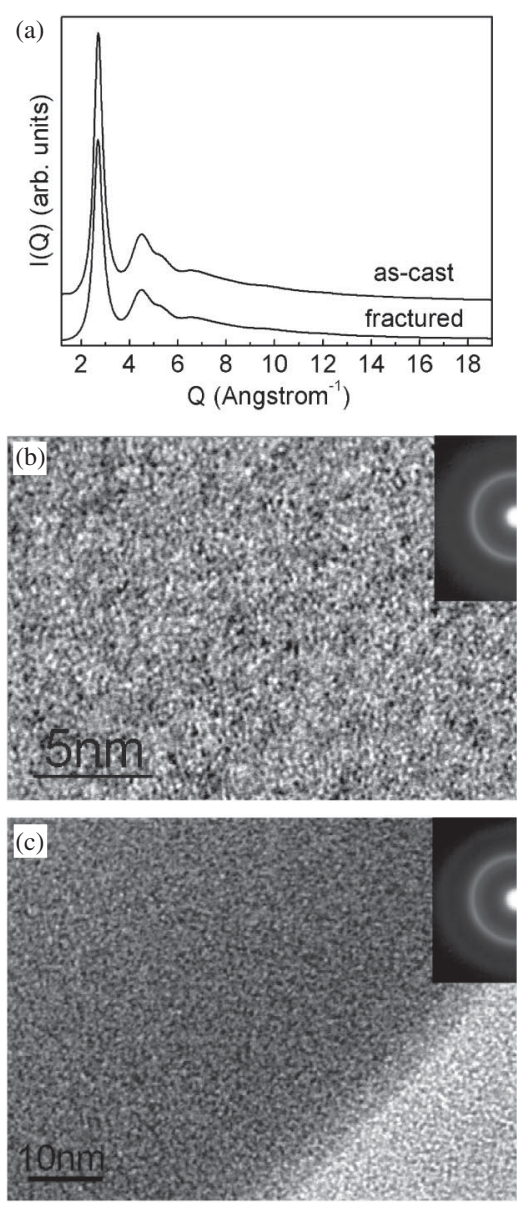

FIG. 3. (a) representative HRXRD patterns of the as-cast and fractured $\mathrm{Cu}_{45} \mathrm{Zr}_{46} \mathrm{Al}_{7} \mathrm{Ti}_{2}$ BMG alloy rods, and (b) HRTEM images and electron diffraction patterns (inset) of the as-cast $\mathrm{Cu}_{45} \mathrm{Zr}_{46} \mathrm{Al}_{7} \mathrm{Ti}_{2}$ BMG alloy rod and (c) of the fractured $\mathrm{Cu}_{45} \mathrm{Zr}_{46} \mathrm{Al}_{7} \mathrm{Ti}_{2}$ BMG alloy rod with plastic strain of $32.5 \%$, taken from the severely deformed part near the fracture surface. Dark and light parts in the HRTEM image (c) are from amorphous matrix and shear band of the fractured alloy, respectively.

formed high resolution TEM and electron diffraction experiments for the as-cast $\mathrm{Cu}_{45} \mathrm{Zr}_{46} \mathrm{Al}_{7} \mathrm{Ti}_{2}$ BMG alloy in Fig. 3(b). No nanocrystallization and nanometer-sized phase separation were detected within the experimental uncertainty of the applied techniques, which further indicates the homogeneous amorphous structure of the as-cast $\mathrm{Cu}_{45} \mathrm{Zr}_{46} \mathrm{Al}_{7} \mathrm{Ti}_{2}$ BMG alloy. Second, the possibility of the high Poisson's ratio to the plasticity was investigated. Ultrasonic measurements were carried out to obtain sound velocities for both as-cast $\mathrm{Cu}_{45} \mathrm{Zr}_{48} \mathrm{Al}_{7}$ and $\mathrm{Cu}_{45} \mathrm{Zr}_{46} \mathrm{Al}_{7} \mathrm{Ti}_{2}$ BMG alloys. Poisson's ratio, acoustic longitudinal velocity, acoustic shear velocity, and density are estimated to be $0.369,4782 \mathrm{~m} / \mathrm{s}, 2176 \mathrm{~m} / \mathrm{s}$, and $7.05 \mathrm{~g} / \mathrm{cm}^{3}$ for as-cast $\mathrm{Cu}_{45} \mathrm{Zr}_{48} \mathrm{Al}_{7}$ and $0.367,4798 \mathrm{~m} / \mathrm{s}, 2197 \mathrm{~m} / \mathrm{s}, 7.01 \mathrm{~g} / \mathrm{cm}^{3}$ for as-cast $\mathrm{Cu}_{45} \mathrm{Zr}_{46} \mathrm{Al}_{7} \mathrm{Ti}_{2}$ BMG alloy rods, respectively. Almost the same Poisson ratios for both BMGs were detected. These results rule out the possibility of high Poisson ratio to the larger plasticity in the quaternary
$\mathrm{Cu}_{45} \mathrm{Zr}_{46} \mathrm{Al}_{7} \mathrm{Ti}_{2}$ BMG alloy in Fig. 1. Third, we try to address the question: do extensive shear band formation and branch result from the deformation-induced nanocrystallization, as suggested by Saida et al. [18], Lee et al. [19], and Chen et al. [20]? Figures 3(a) and 3(c) show the representative HRXRD pattern, TEM image, and electron diffraction pattern for the fractured $\mathrm{Cu}_{45} \mathrm{Zr}_{46} \mathrm{Al}_{7} \mathrm{Ti}_{2}$ BMG alloy at the position near the fracture surface. No sharp Bragg peaks in Fig. 3(a) and no nanocrystalline phases in both amorphous matrix and shear band in Fig. 3(c) can be detected, indicating that no nanocrystallization reaction occurs during the compression test for the $\mathrm{Cu}_{45} \mathrm{Zr}_{46} \mathrm{Al}_{7} \mathrm{Ti}_{2}$ BMG alloy within the experimental uncertainty of the applied techniques.

What is the possible origin for the extensive shear band formation and branch in the $\mathrm{Cu}_{45} \mathrm{Zr}_{46} \mathrm{Al}_{7} \mathrm{Ti}_{2}$ BMG alloy? From the DSC curves recorded for the as-cast alloy rods in Figs. 4 and S2, it is found that the area of the exothermic peak with a broad temperature range before $T_{g}$ dramatically increases from 4 to $9 \mathrm{~J} / \mathrm{g}$ when 2 at. $\%$ Ti is added to the $\mathrm{Cu}_{45} \mathrm{Zr}_{48} \mathrm{Al}_{7}$ alloy. It is well known that prior to $T_{g}$, the exothermic event strongly links with the existence of free volume in BMGs [26]. This indicates that $\mathrm{Ti}$ addition induces large amount of free volume in the as-cast $\mathrm{Cu}_{45} \mathrm{Zr}_{46} \mathrm{Al}_{7} \mathrm{Ti}_{2}$ BMG alloy. This can be understood as follows: Ti-Zr binary phase diagram reveals that $\mathrm{Ti}$ is soluble in both liquid and solid $\mathrm{Zr}$ phases [27]. The values of heat of mixing of $\mathrm{Ti}$ with $\mathrm{Cu}$ and $\mathrm{Al}$ are -9 and $-30 \mathrm{~kJ} / \mathrm{mol}$, respectively, whereas they are -23 and $-44 \mathrm{~kJ} / \mathrm{mol}$ for $\mathrm{Zr}-\mathrm{Cu}$ and $\mathrm{Zr}-\mathrm{Al}$, respectively [28]. Thus, it is not unreasonable to assume that $\mathrm{Ti}$ atoms substitute $\mathrm{Zr}$ atoms in the quaternary $\mathrm{Cu}_{45} \mathrm{Zr}_{46} \mathrm{Al}_{7} \mathrm{Ti}_{2}$ BMG alloy. Finally, smaller Ti atoms $(0.147 \mathrm{~nm}$ in radius) located at $\mathrm{Zr}$ atoms $(0.162 \mathrm{~nm}$ in radius) cause an increase of the free volume in as-cast $\mathrm{Cu}_{45} \mathrm{Zr}_{46} \mathrm{Al}_{7} \mathrm{Ti}_{2}$ BMG alloy, as detected in Fig. 4. In order to further confirm the increase of the amount of free volume induced by smaller Ti atoms, positron annihilation lifetime spectroscopy measurements for both alloys were carried out. Analyses of the annihilation spectra reveal that the average lifetime increases from 212 ps for $\mathrm{Cu}_{45} \mathrm{Zr}_{48} \mathrm{Al}_{7} \mathrm{BMG}$ to $230 \mathrm{ps}$ for $\mathrm{Cu}_{45} \mathrm{Zr}_{46} \mathrm{Al}_{7} \mathrm{Ti}_{2}$ $\mathrm{BMG}$, confirming the enhancement of free volume in the Ti-containing BMG. Finally, we suggest that large amount of randomly distributed free volume in the as-cast $\mathrm{Cu}_{45} \mathrm{Zr}_{46} \mathrm{Al}_{7} \mathrm{Ti}_{2}$ BMG acts as sites for shear band initiation and branch. Numerous and concurrent nucleation of shear bands under the same stress level together with the highly branching of the band restrict the dominant shearing process. The large amount of free volume also reduces the barrier for atoms to move; i.e., it enhances the mobility of the atoms. During compression of the $\mathrm{Cu}_{45} \mathrm{Zr}_{46} \mathrm{Al}_{7} \mathrm{Ti}_{2}$ $\mathrm{BMG}$ alloy, high-density shear bands nucleate from free volume sites, which will propagate and then be branched at other free volume sites. The high mobility of atoms due to large amount of free volume eases the stress relaxation at the crack tip by means of viscoplastic flow and even results 


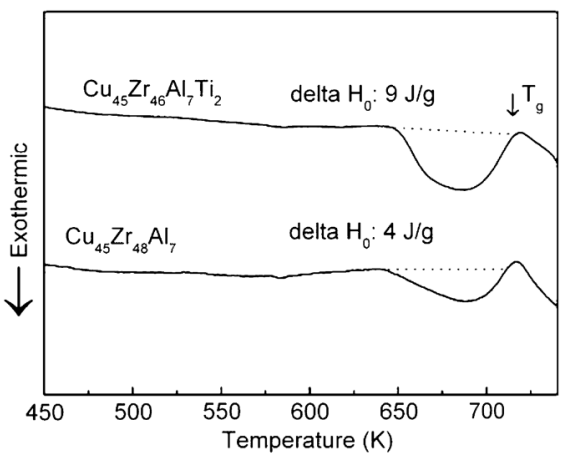

FIG. 4. DSC traces of as-cast (a) $\mathrm{Cu}_{45} \mathrm{Zr}_{48} \mathrm{Al}_{7}$ and (b) $\mathrm{Cu}_{45} \mathrm{Zr}_{46} \mathrm{Al}_{7} \mathrm{Ti}_{2} \mathrm{BMG}$ alloy rods with diameter of $2 \mathrm{~mm}$.

in the healing of the minor cracks. Consequently, increases the critical shear displacement for fracture, causing large plastic deformation for the monolithic $\mathrm{Cu}_{45} \mathrm{Zr}_{46} \mathrm{Al}_{7} \mathrm{Ti}_{2}$ BMG alloy at room temperature, as observed in Fig. 1. This scenario is also supported for the observation of enhanced plastic deformation of BMG alloys at elevated temperatures [29], in which atom mobility largely increases at high temperatures.

In conclusion, without detectable nanometer-scale structural heterogeneity (nanocrystalline phase or nanometerscale phase separation) within the experimental uncertainty of HRXRD and HRTEM to interact with shear band and high Poisson's ratio to branch the shear band, an intrinsic plastic CuZrAl-based BMG with high strength and superior plastic strain of up to $32.5 \%$ was successfully fabricated by Ti minor alloying. The outstanding plasticity was attributed to large amount of randomly distributed free volume, which results in extensive shear band formation, branching, interaction, and self-healing of minor cracks. The mechanism of plasticity presented here suggests that the creation of a large amount of free volume into BMGs by minor alloying or other methods might be a new promising way to enhance plasticity of BMGs.

The authors appreciate S. Q. Ding, H. G. Zhang, and J. Z. $\mathrm{Wu}$ for their assistance in sample preparation. Financial support from the National Natural Science Foundation of China (Grants No. 50341032, No. 50425102, No. 50601021, 50701038, and No. 60776014), Zhejiang University-Helmholtz cooperation fund, the Ministry of Education of China (Program for Changjiang Scholars and the Ph.D research funding) and Zhejiang University is gratefully acknowledged.

*To whom correspondence should be addressed. jiangjz@zju.edu.cn
[1] A. L. Greer, Science 267, 1947 (1995).

[2] W. L. Johnson, MRS Bull. 24, 42 (1999).

[3] A. Inoue, Acta Mater. 48, 279 (2000).

[4] P. S. Stief, F. Spaepen, and J. W. Hutchinson, Acta Metall. 30, 447 (1982).

[5] H. Chen, Y. He, G. J. Shiflet, and S. J. Poon, Nature (London) 367, 541 (1994).

[6] K. M. Flores and R. H. Dauskardt, J. Mater. Res. 14, 638 (1999).

[7] L. Q. Xing, Y. Li, K. T. Ramesh, J. Li, and T. C. Hufnagel, Phys. Rev. B 64, 180201 (2001).

[8] H. C. Yim and W. L. Johnson, Appl. Phys. Lett. 71, 3808 (1997).

[9] C. C. Hays, C. P. Kim, and W. L. Johnson, Phys. Rev. Lett. 84, 2901 (2000).

[10] C. Fan, R. T. Ott, and T. C. Hufnagel, Appl. Phys. Lett. 81, 1020 (2002).

[11] M. L. Lee, Y. Li, and C. A. Schuh, Acta Mater. 52, 4121 (2004).

[12] T. Wada, A. Inoue, and A. L. Greer, Appl. Phys. Lett. 86, 251907 (2005).

[13] C. Fan and A. Inoue, Appl. Phys. Lett. 77, 46 (2000).

[14] Y.C. Kim, J. H. Na, J. M. Park, D. H. Kim, J. K. Lee, and W. T. Kim, Appl. Phys. Lett. 83, 3093 (2003).

[15] J. Das, M. B. Tang, K. B. Kim, R. Theissmann, F. Baier, W. H. Wang, and J. Eckert, Phys. Rev. Lett. 94, 205501 (2005).

[16] K. B. Kim, J. Das, F. Baier, M. B. Tang, W. H. Wang, and J. Eckert, Appl. Phys. Lett. 88, 051911 (2006).

[17] A. Inoue, W. Zhang, T. Tsurui, A. R. Yavari, and A. L. Greer, Philos. Mag. Lett. 85, 221 (2005).

[18] J. Saida, A. D. H. Setyawan, H. Kato, and A. Inoue, Appl. Phys. Lett. 87, 151907 (2005).

[19] S. W. Lee, M. Y. Huh, E. Fleury, and J. C. Lee, Acta Mater. 54, 349 (2006).

[20] M. W. Chen, A. Inoue, W. Zhang, and T. Sakurai, Phys. Rev. Lett. 96, 245502 (2006).

[21] K. F. Yao, F. Ruan, Y. Q. Yang, and N. Chen, Appl. Phys. Lett. 88, 122106 (2006).

[22] K. B. Kim, J. Das, S. Venkataraman, S. Yi, and J. Eckert, Appl. Phys. Lett. 89, 071908 (2006).

[23] J. Schroers and W. L. Johnson, Phys. Rev. Lett. 93, 255506 (2004).

[24] D. H. Bae, S. W. Lee, J. W. Kwon, X. D. Wang, and S. Yi, Mater. Sci. Eng. A 449-451, 111 (2007).

[25] See EPAPS Document No. E-PRLTAO-100-040808 for supplementary figures. For more information on EPAPS, see http://www.aip.org/pubservs/epaps.html.

[26] A. Slipenyuk and J. Eckert, Scr. Mater. 50, 39 (2004).

[27] Binary Alloy Phase Diagrams, edited by T. B. Massalski, H. Okamoto, P. R. Subramanian, and L. Kacprzak (ASM International, Metals Park, OH, 1990), 2nd ed.

[28] A. Takeuchi and A. Inoue, Mater. Trans., JIM 46, 2817 (2005).

[29] A. Inoue, B. L. Shen, H. Koshiba, H. Kato, and A. R. Yavari, Nat. Mater. 2, 661 (2003). 